\title{
Bioprocessing of Barley for Food-Producing Ruminants: A Workable Dilemma
}

\section{Akbar Nikkhah*}

Chief Highly Distinguished Professor, Department of Animal Sciences, Faculty of Agricultural Sciences, University of Zanjan, Zanjan, Iran

*Corresponding author: Akbar Nikkhah, Chief Highly Distinguished Professor, Department of Animal Sciences, Faculty of Agricultural Sciences, University of Zanjan, Zanjan, 313-45195, Iran, Tel: 0098-2412801; Email: anikkha@yahoo.com, nikkhah@znu.ac.ir

Rec date: May 22, 2014; Acc date: May 23, 2014; Pub date: May 30, 2014

Copyright: () 2014 Nikkhah A. This is an open-access article distributed under the terms of the Creative Commons Attribution License, which permits unrestricted use, distribution, and reproduction in any medium, provided the original author and source are credited.

\section{Editorial}

This editorial seeks to help eradicate confusions, enlighten the current perceptions, and highlight a global need to develop feasible guidelines for optimum bioprocessing of barley grain (BG). The optimum processing techniques must result in moderated rumen fermentation of starch and protein, improved rumen microbial protein synthesis, reduced risks of Sub-Acute Rumen Acidosis (SARA) and pro-inflammatory immune responses, and improved food-producing dairy and beef cattle performance and health.

Mismanagement in processing BG may easily make a fiasco from the pearl of cereals [1]. Bioprocessing considerably affects rate, extent, and site of nutrient digestion. Barley grain is commonly either rolled, tempered, steam-flaked, ground or roasted. Tempering, dry-rolling and steam-rolling are common in North America, Australia and Western Europe, while grinding is common in Iran [2]. However, the most economical and health-improving technique under varying management conditions remains a global dilemma.

Aggressive and high-pressure heat exposure may reduce barley degradation rate. This reduction is important in vivo, especially shortly post-feeding when rumen fermentation peaks. Such moderated barley degradation rate can improve feed efficiency likely through increased rumen $\mathrm{pH}$ and attenuated Sub-Acute Rumen Acidosis during fermentation peaks, and increased small intestinal escape or partiallydigested starch assimilation [3]. Likewise, flame roasting of BG may reduce rumen degradation. The literature fueled by farm experience suggests that BG may be utilized more efficiently when fed in combination with corn grain rather than fed alone.

Based on NRC [4] recommendations, dairy diets should contain 25 to $28 \%$ NDF, $75 \%$ of which must be supplied by forages. This is needed to adequate chewing and healthy rumen function, to prevent milk fat depression and laminitis. Barley grain based diets usually provide greater concentrate NDF than corn based diets. However, due to inadequate effectiveness of barley NDF in stimulating chewing and saliva production plus the faster degradation of BG vs. corn, BG-fed cows require more effective forage fiber than corn-fed cows [5]. Recent data demonstrated that expensively steam-rolled BG is no superior to simply finely ground BG if dietary BG inclusion rate is kept logically moderate at $\leq 300 \mathrm{~g} / \mathrm{kg}$ of diet dry matter [6]. Even at $350 \mathrm{~g} / \mathrm{kg} \mathrm{BG}$, except modest improvement in feed efficiency, milk production and DM intake was similar between ground and steam-rolled barley fed cows [7].
Overfeeding BG is a shortest path to SARA, triggered inflammation, and depressed immunity and production $[1,2,3,8]$. Whilst is BG a supreme source of rapidly released energy and nitrogen for effective rumen microbial growth and volatile fatty acids production, its dietary use and bioprocessing technique will be an art to allow ruminant production and health improve concomitantly [2]. As much as famed the pearl of cereals for persistent peaks in beef and dairy production, improper feeding of no other grain can be as much economically distressing.

When included in right amounts, bioprocessing techniques that control overly rapid rumen fermentation of BG (e.g., coarse grinding, extensive steam-rolling, tempering) should be manageably adopted to help optimize microbial and host metabolism and health.

\section{Acknowledgments}

The Iranian Ministry of Science, Research and Technology and University of Zanjan are thankfully acknowledged for supporting the author' global programs of optimizing science edification in the new millennium.

\section{References}

1. Nikkhah A (2012) Barley grain for ruminants: A global treasure or tragedy. J Anim Sci Biotechnol 3: 22.

2. Nikkhah A (2011) Barley grain for rumen and ruminants: overmodernized uses of an inimitable fuel. In Barley: Production, Cultivation and Uses. Nova Science Publishers, New York, USA.

3. Nikkhah A (2011) Optimizing barley grain use by dairy cows: a betterment of current perceptions. Nova Science Publishers, New York, USA: 165-178.

4. (2001) National Research Council: Nutrient Requirements of Dairy Cattle. 7th rev edtn, National Academy Press, Washington DC, USA.

5. Beauchemin KA, Rode LM (1997) Minimum versus optimum concentrations of fiber in dairy cow diets based on barley silage and concentrates of barley or corn. J Dairy Sci 80: 1629-1639.

6. Sadri H, Ghorbani GR, Alikhani M, Babaei M, Nikkhah A (2007) Ground, dry-olled, and steam-rolled barley grain for midlactation Holstein cows. Anim Feed Sci Technol 138: 195-204.

7. Soltani A, Ghorbani GR, Alikhani M, Samie A, Nikkhah A (2009) Ground versus steam-rolled barley grain for lactating cows: a clarification into conventional beliefs. J Dairy Sci 92: 3299-3305.

8. Emmanuel DGV, Dunn MS, Ametaj BN (2008) Feeding high proportions of barley grain stimulates an inflammatory response in dairy cows. J Dairy Sci 91: 606-614. 